\title{
An Assessment of the Surgical Results of the Site-Directed Surgical Treatment in Obstructive Sleep Apnoea Syndrome
}

\author{
D. R. Kandel*, A. Thakar, S. C. Sharma, S. K. Sharma, A. Trikha, G. Shukla, A. S. Bhalla, R. Kumar, \\ R. C. Deka \\ MS ENT and HNS, Bharatpur, Nepal \\ Email: ^drdrkandel@gmail.com
}

How to cite this paper: Kandel, D.R., Thakar, A., Sharma, S.C., Sharma, S.K., Trikha, A., Shukla, G., Bhalla, A.S., Kumar, R. and Deka, R.C. (2020) An Assessment of the Surgical Results of the Site-Directed Surgical Treatment in Obstructive Sleep Apnoea Syndrome. International Journal of Otolaryngology and Head \& Neck Surgery, 9, 111-123.

https://doi.org/10.4236/ijohns.2020.94015

Received: May 8, 2020

Accepted: June 28, 2020

Published: July 1, 2020

Copyright $\odot 2020$ by author(s) and Scientific Research Publishing Inc. This work is licensed under the Creative Commons Attribution International License (CC BY 4.0).

http://creativecommons.org/licenses/by/4.0/

\section{(c) (i) Open Access}

\begin{abstract}
Background: Obstructive sleep apnea (OSA) has cardiovascular, neurological, and social complications. Surgical treatment has the potential to improve airway patency but when and which surgery should be done is a controversy. Aims and objectives: To estimate the site of obstruction in patients with OSAS and to assess the surgical results of the site (of obstruction) directed surgical treatment. Methodology: Twenty patients with OSAS were included in the study with Eight adults and Twelve children. It was a prospective study. All patients were assessed for the airway collapse and surgery was done accordingly. Repeat PSG was done after surgery for success rate after 4 months of follow up. Result: 17 patients successfully completed the follow-up. Four (50\%) adults and Two (17\%) children have grade I or II tonsils while Four (50\%) of adults and Ten (83\%) children have tonsil size grade III or IV. Seven $(88 \%)$ adults and one (8\%) of the children have adenoid hypertrophy up to grade II. One adult (12\%) and nine children (75\%) have grade III Adenoid size. Two children (17\%) have Adenoid grade IV size. In Four patients retropalatal more than retroglossal collapse was found (50\%). One patient (12\%) had retroglossal more than retropalatal collapse other one had only retropalatal collapse, and the other one had retroglossal collapse. ESS (Epworth sleepiness scale) decreased postoperatively in both groups. There is a significant change in AHI with the median pre-op AHI being 40.19 to median post-op AHI being 11.35 with a p-value 0.017. Apnea-hypopnea index (AHI) in children pre-operatively was 12.98 (median) changed to 2.15 (median) which is statistically significant. Only one adult patient (12\%) is surgically cured while in five patients (63\%) surgical success achieved with a surgical success rate of $5 / 8(63 \%)$. Whereas only one patient is surgically cured $1 / 8$ (13\%). Eight patients achieved surgical success with a total success rate of $8 / 9$
\end{abstract}


(89\%). While only two patients achieved surgical cure (23\%) among children. Conclusion: The outcome of site-directed surgical treatment is that it is a satisfactory way of treatment of OSAS with an overall success rate of $76 \%$.

\section{Keywords}

Obstructive Sleep Apnoea, Polysomnography, Retroglossal, Apnoea

Hypopnoea Index

\section{Introduction}

Obstructive sleep apnea (OSA) is a common sleep-related breathing disorder. The prevalence in middle-aged males is between $1.3 \%$ - 4\% [1] [2] and in children $1 \%-3 \%$ [3]. The OSA S (obstructive sleep apnoea syndrome) is characterized by repeated partial or complete closure of the pharynx, gasping episodes, sleep fragmentation, and day time sleepiness [4]. Risk factors are obesity, male gender, age, ethnicity, and craniomaxillofacial abnormalities [5] [6]. Others are smoking, alcohol intake, familial predisposition [7]. Clinical features of OSA are poor sleep pattern and witnessed breath-hold, excessive day time sleepiness, nocturia. Complications of OSAS are cognitive impairment, poor memory, irritability, depression, arrhythmia, heart failure ischaemic heart disease, systemic and pulmonary hypertension, neurological complication and even mortality [8] [9] [10] [11]. Treatment by CPAP is considered as gold standard however it leads to the patient being dependent on the CPAP machine which is required to be worn and switched on whenever the patient sleeps. This may be unacceptable to some patients and compliance to this treatment can be variable. Surgical treatment has the potential to improve airway patency and offer a more permanent cure. Surgical treatments have however been limited by the inadequacy of current evaluation techniques to accurately localize the site of dynamic obstruction, and the exact indications for the various proposed surgical procedures remain not precisely elucidated.

\section{Aims and Objective}

- To estimate the site of obstruction in patients with OSAS.

- To assess the surgical results of site (of obstruction) directed surgical treatment of OSAS.

\section{Methodology}

This is a prospective study conducted in the period of 2011-2012 as a thesis for the degree of MS ENT.

Twenty patients with OSAS were included in the study with Eight adults and Twelve pediatric patients. The Adult cases were classified as Group I and pediatric patients as Group II. The age range in group I is 20 - 54 yrs. In group II range 
is $4-12$ yrs.

This is a prospective study. Informed and written consent was obtained from all patients or their parents in the case of children. The study was done in the Department of Otorhinolaryngology, AIIMS, New Delhi.

\section{INCLUSION CRITERIA:}

1) Diagnosed case of OSAS of all severity as confirmed by polysomnography (PSG).

2) Patients opting for the definitive treatment of OSAS.

3) Patients with an identifiable site of obstruction.

4) Patients who did not opt for CPAP and willing to undergo surgical intervention.

7) Patient consenting for the study.

\section{EXCLUSION CRITERIA:}

1) Patients having a preference for CPAP use.

2) Patients having a significant systemic complication

3) Patients with co-morbidities precluding surgical intervention.

The All India Institute of Medical Sciences (AIIMS), New Delhi, Ethics Committee granted ethical clearance for the study on $7^{\text {th }}$ March 2011 . The study was commenced thereafter. Independent variables like obesity, Tonsil size, Adenoid size, other anatomical abnormality, site of obstruction, Epworth sleepiness scale, pre-operative PSG parameters and dependent variables like Postoperative PSG parameters and success rate of surgery were measured.

Polysomnography was done preoperatively for diagnosis. After confirming the diagnosis we did Müller's maneuver to identify the site of obstruction in adult patients or clinical examination in children. Postoperative clinical evaluations were done at periods of one week, four weeks, and at the fourth month. Postoperative Polysomnography was undertaken in the fourth postoperative month.

Müller's maneuver [12] was done with flexible fiberoptic endoscopy in an OPD setting. In this procedure, the patient is asked to do forced inspiratory effort with the mouth and nose closed and different levels, the oropharyngeal level (soft palate and the junction of the nasopharynx) and the hypopharyngeal level (just above the epiglottis) and the degree of airway collapse would be noted.

At each post-op visit patients were asked about subjective improvement in symptoms and daytime sleepiness was assessed by the Epworth Sleepiness Scale. Postoperative Polysomnography was undertaken at 4 - 6 months post-operatively.

Tonsil sizes are graded from GradeI to Grade IV according to Friedman M et al. [13]. Grade I tonsils were in the tonsillar fossa, barely seen behind the anterior pillars. Grade II tonsils were visible behind the anterior pillars. Grade III tonsils extended three-quarters of the way to the midline. Grade IV tonsils were completely obstructing the airway, also known as "kissing" tonsils

For adenoids a grading scale of I-IV was developed by J. Clemens et al. [14]. Grade I: has adenoid 1/3 the vertical height of the choana; Grade II: up to 2/3; 
Grade III: from $2 / 3$ to nearly all but not the complete filling of the choana and Grade IV: with complete choanal obstruction.

Statistical analysis was done with SPSS Advanced Statistics, version 17.0, in coordination with the Department of Biostatistics, All India Institute of Medical Sciences. The analysis was done with the chi-square test and the Wilcoxon rank-sum (Mann-Whitney) test.

Results: Total patients included were 20 but only 17 patients successfully completed the follow-up. Age distribution in adults ranges from 20 to 54 with mean of $36.88 \pm 11.28$. And in children range is from 4 to 12 with mean $6.96 \pm$ 2.84 .

Five children (42\%) were classified as undernourished. Two adults (25\%) and three children (25\%) had a normal BMI. Two of the adults (25\%) and one child (8\%) were overweight. Four adults (50\%) and three children (25\%) were obese (Figure 1).

Four adults (50\%) and two of the children (17\%) have grade I or II tonsils. $50 \%$ of adults (4) have tonsil size grade III or IV while in children $83 \%$ of children (10) have tonsil size grade III or IV (Figure 2).

Seven adults (88\%) and one of the children have up to grade II adenoid hypertrophy. One adult (12\%) and nine children (75\%) have grade III Adenoid size. None of the adults and two children (17\%) has Adenoid grade IV size (Figure 3).

Two adult patients (25\%) and none of the pediatric patients had macroglossia. Maxillary hypoplasia was present in three adult patients (38\%) but in none of the children. Mandibular hypoplasia present in three adults (38\%) and one child (8\%). Turbinate hypertrophy was present in four adult patients (50\%) but in none of the children. Significant DNS were present in all adult patients and two children (17\%) (Figure 4).

The Müller's maneuver was only undertaken for adult patients. In Four patients retropalatal more than retroglossal collapse was found (50\%). In one patient $(12 \%)$ each retroglossal more than retropalatal collapse, only retropalatal collapse, and only retroglossal collapse were present respectively. The other one patient has no upper airway collapse (Figure 5).

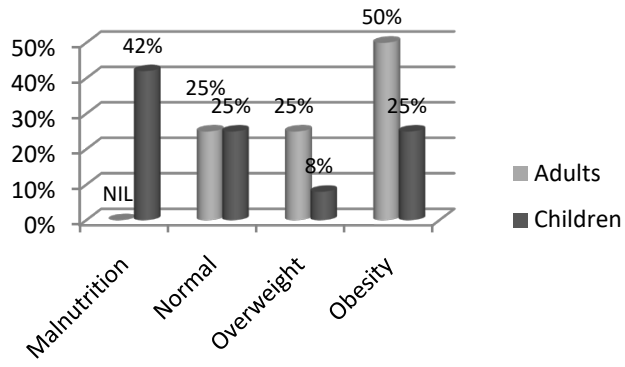

Figure 1. Distribution of BMI in adults and children. Obesity is more prevalent among adults. 


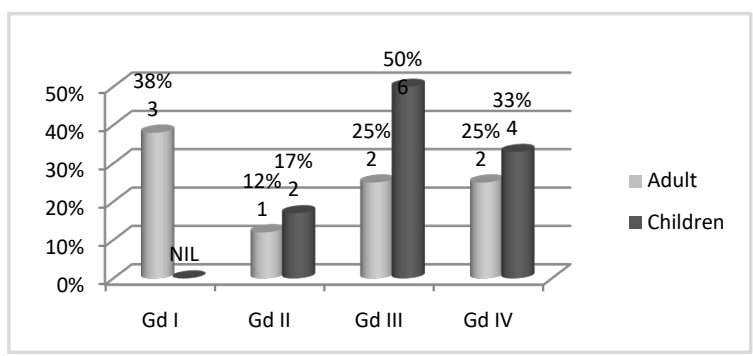

Figure 2. Distribution of tonsil size in adults and children. Tonsils are larger among children than adults.

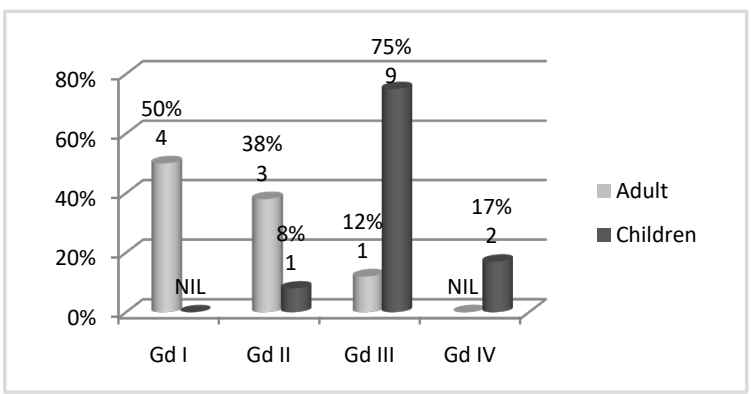

Figure 3. Distribution of adenoid size in adult and children. Adenoids are larger in children than in adults.

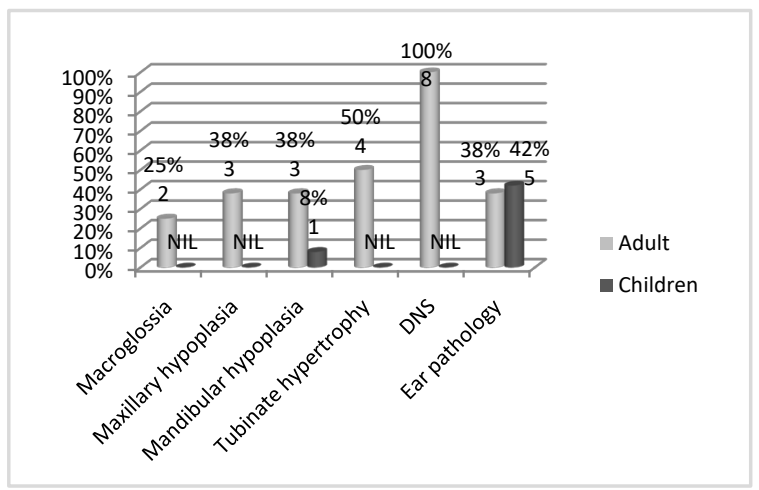

Figure 4. Prevalence of other anatomical abnormality in adults and children.

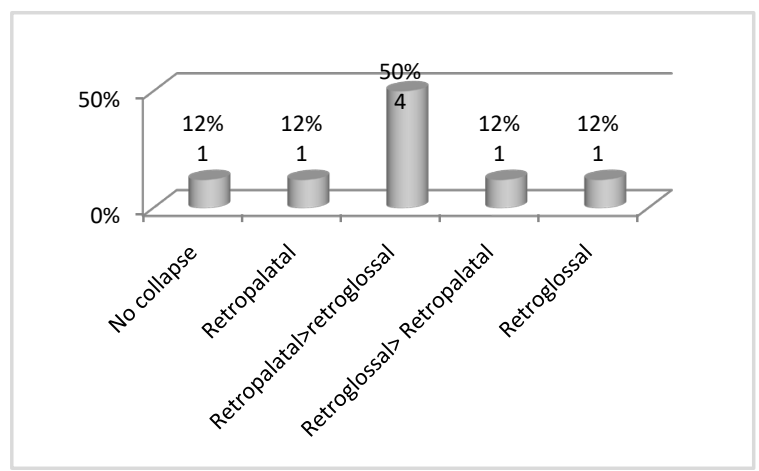

Figure 5. Different site of obstruction according to Müller's maneuver. Most common site is Retropalatal > Retroglossal collapse. 
Two adult patients (25\%) underwent Tonsilloadenoid resection (TAR) + Septoplasty. Two other adult patients underwent Uvulopalatopharyngoplasty (UPPP) + Septoplasty. Other One adult patient underwent UPPP + Inferior turbinate resection (ITR). One adult patient underwent UPPP + septoplasty + ITR (8\%). One adult patient underwent Genioglossus advancement + Hyoid suspension + Septoplasty $(8 \%)$. While in children Eleven patients underwent TAR (91\%) and other one underwent Adenoidectomy.

All patients showed improvement in the postoperative period. Five adults (62\%) showed only partial improvement in pre-op symptoms while all children showed complete improvement.

Epworth sleepiness scale (ESS) decreased postoperatively in both groups. The change in ESS pre-op to post-op is significant in case of adult while it is not in the case of children (Table 1 ).

In adult patients pre-operatively there were one (12\%) mild, one (12\%) moderate and six (75\%) severe cases. Post-operatively improved to one normal (12\%), five mild (63\%) and two severe (25\%) in severity.

In the context of adult patient's pre-operative and post-operative polysomnographic parameters, there is a significant change in AHI with the median pre-op AHI being 40.19 to median post-op AHI being 11.35 with p-value 0.017 . Apnoea index (AI) changed from 21.45 to 1.9 with p-value 0.05. Similarly, Desaturation Index (DI) changed from 30.5 to 15.45 with p-value 0.017. Arousal Index (AI) changed from 26.25 to 20.03 with p-value 0.077 which is not significant (Table 2).

In children Pre-operatively two patients (22\%) were mild type, four (44\%) were moderate and three (33\%) were severe in the severity of OSAS. Post-operatively they improved to two $(22 \%)$ with normal, six $(67 \%)$ with very mild, and one (11\%) with mild in severity (Table 3).

Apnea-hypopnea index (AHI) pre-operatively were 12.98 (median) changed to 2.15 (median) which is statistically significant. Similarly, pre-operative AI (apnea index) changed from 28.05 to 0.95 which is significant statistically. DI (desaturation index) also changed from median value 10.9 to 1.75 also statically significant. AI changed from median value 19.35 to 9.9, statistically significant. Minimum saturation changed from $64.5 \%$ to $96 \%$, statically significant. Similarly, Mean saturation changed significantly from $95.5 \%$ to $98 \%$. AHI in adult and children are significantly different in preoperative and in post-operative cases.

As per the Sher Criteria for assessment of surgical success (i.e. reduction of $\mathrm{AHI}$ to at least $50 \%$ of pre-operative $\mathrm{AHI}$ and $\mathrm{AHI} \leq 20$ ), only one adult patient (12\%) is surgically cured. In this patient, GGA (Figures 6-8) + HS + Septoplasty was done. In five patients (63\%) surgical success achieved with a surgical success rate of 5/8 (63\%). Whereas only one patient is surgically cured 1/8 (13\%) (Table 4).

In the pediatric group, Eight patients achieved surgical success with a total success rate of $8 / 9$ (89\%). While only two patients achieved surgical cure (23\%) (Table 5). 


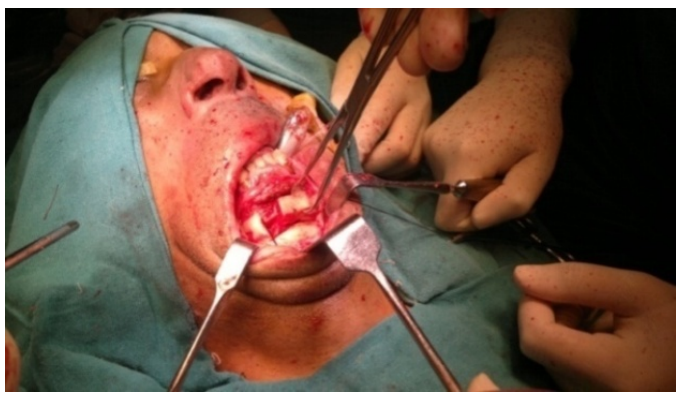

Figure 6. Osteotomy done.

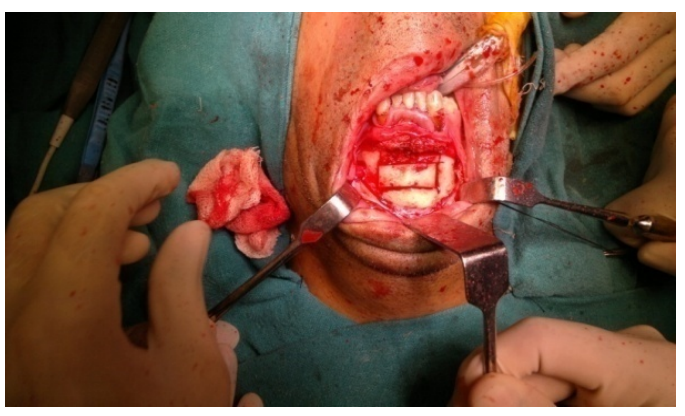

Figure 7. Geniotubercle fragment pulled forward.

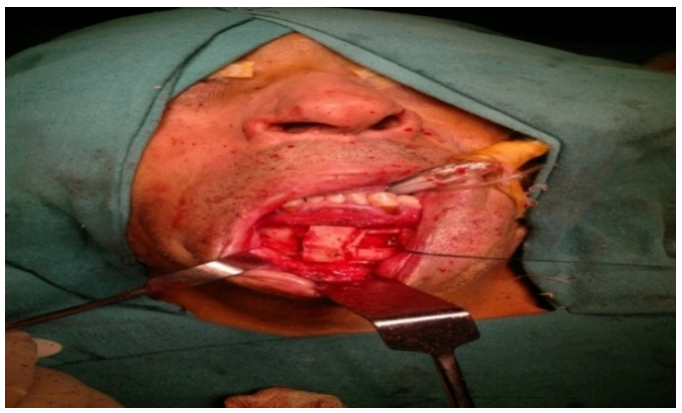

Figure 8. The fragment is fixed with mini screw.

Table 1. The preoperative and post operative Epworth sleepiness scale. Post-operaatively decreased more in adults thanin children. (Data given are Mean $+\mathrm{SD}$ ).

\begin{tabular}{cccc}
\hline & Pre. op & Post op & P-value \\
\hline Adults & $9.6 \pm 3.7$ & $4 \pm 2.67$ & 0.046 \\
Children & $6.33 \pm 1.0$ & $3.44 \pm 1.69$ & 0.190 \\
\hline
\end{tabular}

Table 2. Analysis of pre and post operative polysomnographic parameters. The parameters decreased significantly after surgery.

\begin{tabular}{cccc}
\hline PARAMETERS & PRE-OP. & POST-OP & P VALUE \\
\hline AHI & $40.195(24)$ & $11.35(13.55)$ & 0.017 (Significant) \\
AI & $21.45(17)$ & $1.9(9.73)$ & 0.05 (Significant) \\
DI & $30.5(23)$ & $15.45(13.54)$ & 0.017 (Significant) \\
Ar.I & $20.2(27)$ & $20.6(11.54)$ & 0.0779 (Not Significant)
\end{tabular}

(AHI-Apnea hypopnea index, AI-Apnea Index, DI-desaturtion index, Ar. I-Arousal Index). 
Table 3. Comparison between pre-operative polysomnographic value and post-operative value in children. The parameters decreased significantly after surgery.

\begin{tabular}{cccc}
\hline PARAMETERS & $\begin{array}{c}\text { PRE-OP. (median) } \\
( \pm \text { SD })\end{array}$ & $\begin{array}{c}\text { POST-OP (median) } \\
( \pm \text { SD })\end{array}$ & p - VALUE \\
\hline AHI & $12.98( \pm 19.77)$ & $2.15( \pm 2.65)$ & 0.012 (Significant) \\
AI & $28.05( \pm 20.13)$ & $0.95( \pm 1.38)$ & 0.012 (Significant) \\
DI & $10.9( \pm 8.33)$ & $1.75( \pm 2.24)$ & 0.012 (Significant) \\
\hline
\end{tabular}

(AHI-Apnea hypopnea index, AI-Apnea Index, DI-desaturtion index).

Table 4. Applying Sher's criteria to calculate success rate in adults.

\begin{tabular}{|c|c|c|c|c|c|}
\hline $\begin{array}{l}\text { Case } \\
\text { No. }\end{array}$ & Surgical Procedure & $\begin{array}{c}\text { Pre } \\
\text { op AHI }\end{array}$ & $\begin{array}{c}\text { Post } \\
\text { op AHI }\end{array}$ & $\begin{array}{c}\text { Surgical success } \\
\text { (reduction of AHI to atleast } \\
50 \% \text { of pre-operative AHI } \\
\text { and AHI } \leq 20 \text { ) }\end{array}$ & $\begin{array}{c}\text { Surgical } \\
\text { cure } \\
(\mathrm{AHI}<5)\end{array}$ \\
\hline 1. & TAR + Septoplasty & 32.1 & 30.3 & - & - \\
\hline 2. & UPPP + Septoplasty & 39.86 & 6.69 & + & - \\
\hline 3. & UPPP + Septoplasty & 49.2 & 14.8 & + & - \\
\hline 4. & TAR + Septoplasty & 83.24 & 14.98 & + & - \\
\hline 5. & ITR & 8.9 & 7 & - & - \\
\hline 6. & UPPP + Septoplasty + ITR & 40.5 & 41.5 & - & - \\
\hline 7. & GGA + HS + Septoplasty & 23.1 & 2 & + & + \\
\hline 8. & UPPP + ITR & 69.5 & 7.9 & + & - \\
\hline Total & & & & $5 / 8(63 \%)$ & $1 / 8(13 \%)$ \\
\hline
\end{tabular}

Table 5. Applying Sher criteria to calculate success rate in children.

\begin{tabular}{cccccc}
\hline $\begin{array}{c}\text { Case } \\
\text { No. }\end{array}$ & $\begin{array}{c}\text { Surgical } \\
\text { Procedure }\end{array}$ & $\begin{array}{c}\text { Pre op } \\
\text { AHI }\end{array}$ & $\begin{array}{c}\text { Post op } \\
\text { AHI }\end{array}$ & $\begin{array}{c}\text { Surgical success rate (Sher criteria) } \\
\text { (reduction of AHI to atleast 50\% of } \\
\text { pre-operative AHI and AHI } \leq 20)\end{array}$ & $\begin{array}{c}\text { Surgical } \\
\text { cure } \\
\text { (AHI < 1) }\end{array}$ \\
\hline 1. & TAR & 77.04 & 2 & + & - \\
2. & TAR & 10 & 4.1 & + & - \\
3. & TAR & 13.4 & 8.6 & - & - \\
4. & TAR & 10.1 & 2.3 & + & - \\
5. & TAR & 34.02 & 1.5 & + & - \\
6. & TAR & 14.52 & 2.5 & + & + \\
7. & TAR & 17.98 & 0.7 & + & + \\
8. & Adenoidectomy & 5.9 & 0.3 & + & - \\
9. & TAR & 12.56 & 1.2 & + & $2 / 9(23 \%)$ \\
\hline
\end{tabular}

Two adult patients who had undergone UPPP (25\%) had persistent pain in the throat. Difficulty in swallowing was present in one adult patient (12\%) who had undergone genioglossus advancement and hyoid suspension that also re- 
solved in the third follow up. One child who underwent TAR had bleeding from mouth on the $8^{\text {th }}$ post-op day. The child was admitted in the hospital and managed conservatively.

\section{Discussion}

OSA is important due to its increasing prevalence worldwide. Despite being so common, over $80 \%$ of individuals with moderate to severe disease are never diagnosed. The clinical presentation, pathophysiology, polysomnographic characteristics, and treatment differ between children and adults [15]. So we have separated adults and children as two separate groups for easier and accurate comparison.

$50 \%$ of adults have tonsil size grade III or IV while in children $83 \%$ of children have tonsil size grade III or IV. Barceló X et al. found $17 \%$ grade $0,41.2 \%$ grade I, $36 \%$ grade II, and $15 \%$ grade 3 tonsil size in a study conducted in 300 patients. In our study, we found more tonsil of grade III and IV (50\%) [16]. The more prevalence of adenotonsillar hypertrophy in children than in adult is a well-known fact as lymphatic hyperplasia peaks in $5-10$ yrs. of age. But the difference between the incidence of tonsillar hypertrophy among adults in our study than the literature may be due to GERD being more common in our part of the world. The most common risk factor in children is adenotonsillar hypertrophy [17]. Our study also finds s similar result in children.

$92 \%$ of children and $12 \%$ of adults have adenoid size grade III/IV. Published literature also shows a similar result in children [17]. Kapusuz Z. et al. [18] showed the prevalence of adenoid hypertrophy to be $26.5 \%$ in a study done among the patient attended the Otolaryngology department for treatment, retrospectively. Among them 14\% were grade I, $8 \%$ were grade II, $4 \%$ were grade III. Our study and this published literature by Kapusuz Z. et al. [18] emphasize the role of adenotonsillar hypertrophy in adult OSAS.

Sleep nasendoscopy was done in one pediatric patient in whom pre-operative localization of the site of obstruction remained ambivalent. He has grade II/III adenoid hypertrophy and grade II tonsillar hypertrophy. Sleep nasendoscopy indicated retroglossal collapse with the normal retropalatal area.

All patients showed improvement in the postoperative period. Five adults (62\%) showed only partial improvement in pre-op symptoms while all children showed complete improvement. As only one adult is surgically cured and others having a mild form of the disease so they might be having some symptoms. While in children all except one who is having mild form are having very mild OSAS $(\mathrm{AHI}<5)$.

ESS decreased postoperatively in both groups. The change in ESS pre-op to post-op is significant in the case of adults $(\mathrm{p}<0.05)$ while it is not in the case of children. The average of ESS in children was $6.33 \pm 3.7$ which is normal in itself. As the children were not having significant sleepiness before the operation so there is no significant change postoperatively.

In our study also we found upper airway collapse in all adult OSAS patient 
(88\%) except one who has mild OSAS (AHI-9/hr). The most common finding was retropalatal > retroglossal in $50 \%$ of cases signifying that mixed collapse is most common but retropalatal collapse is more prominent than retroglossal. According to Li W et al. [19], the most common site of obstruction is retropalatal and multisite obstruction. Our study also supports the findings.

Postoperatively in adults pre-op AHI value changed from $40.19 \pm 24$ to 11.35 \pm 13.55 with p-value 0.017. Similarly Apnoea index, Desaturation Index also changed significantly. Arousal Index (AI) did not change significantly. 63\% surgical success rate was achieved in adults and $13 \%$ was a surgical cure rate. In children, AHI changed from $12.98 \pm 19.77$ to $2.15 \pm 2.65$ (p-value 0.012 ) which is significant. In children, the surgical success rate achieved was $89 \%$ and $23 \%$ was the cure rate. Similarly, the Apnea index, the Arousal index, the Desaturation index, Mean saturation, and Minimum saturation also changed which was statically significant $(\mathrm{p}<0.05)$, overall success rate being $76 \%$.

It is well-recognized that patients treated with UPPP alone have high surgical success rates for Friedman stage I but low success rates for stage III [20] [21]. This is because the stage III has retroglossal collapse whereas UPPP mainly corrects velopharyngeal obstruction. It also emphasizes the importance of site-directed surgical treatment. Sher et al. [22] conducted a meta-analysis of 37 published articles on the efficacy of UPPP for OSAS and found a success rate of $40.7 \%$ for UPPP in nonselected patients with OSAS. Friedman et al. [20] retrospectively reviewed 134 patients who underwent UPPP and reported that the overall success rate was $31.3 \%(42 / 134)$ regardless of anatomy-based stages. Hence the same surgery has different outcomes in a different study. While in those with retropalatal obstruction as the only site of obstruction UPPP has more success rate than that in others in whom multiple sites of obstruction present or it was not localized at all. In our study, all the retropalatal obstruction patients underwent either UPPP \pm nasal surgery depending on the presence or absence of nasal obstruction or tonsilloadenoid resection with or without septoplasty. So our result of site directed surgical treatment is superior (success rate of $63 \%$ ) to nonselected (where the site of obstruction was not localized before surgery) surgery result (success rate of $40.7 \%$ and $31.3 \%$ [21]).

We have done genioglossus advancement with hyoid suspension and septoplasty surgery in one patient who has retroglossal collapse as a site of obstruction with significant collapse and was totally cured of the disease. Fibbi et al. [23] proposed genioglossus advancement surgery in patients with retrolingual collapse airway with success rate of 75 .

So the surgery should be directed towards its underlying cause to cure the symptoms. The sites of obstruction in OSAS patients are usually found to be multiple. So sometimes a single procedure may not be sufficient especially when multiple sites are involved. Stow NW et al. [24] did simultaneous adenotonsillectomy and nasal surgery as a treatment for obstructive sleep apnea (OSA). They found that in selected adult subjects, tonsillectomy with intercurrent nasal 
surgery should be considered as an effective treatment for OSAS.

In most children with documented OSAS and with adenotonsillar hypertrophy, and adenotonsillectomy is the recommended first-line therapy according to the practice guidelines established by the American Academy of Pediatricians for childhood OSAS [25]. In our study also we have found results (89\% success rate) comparable to the published result of success rate of surgical treatment of OSAS.

In our study, early complications include pain, difficulty in swallowing, velopharyngeal insufficiency that was also resolved in one week of duration. One adult patient had difficulty in breathing immediately after extubation so was kept in ICU for overnight. Difficulty in swallowing present in one adult patient (12\%) who had underwent genioglossus advancement and hyoid suspension and septoplasty as a surgical procedure that also resolved in the third follow up. Post-operative primary hemorrhage, delayed hemorrhage, temporal velopharyngeal insufficiency, and foreign body sensation at pharynx were documented complications in UPPP surgery [26]. Our study did not show any significant complications.

There are some demerits of our study also. A small number of sample size, follow up of only four months period, the diagnostic investigation polysomnography was done in three different sleep laboratory of the institute (though pre-operative and post-operative polysomnography of each patient was done in the same sleep laboratory) are our demerits.

\section{Conclusion}

The outcome of site-directed surgical treatment is a satisfactory way of treatment of OSAS with an overall success rate of $76 \%$ according to Sher criteria. The treatment outcome is more successful in cases of children (89\% success rate) than adults (63\% success rate). The phase I site-directed surgical treatment at the same time is safe as it is not associated with any major complication.

\section{Conflicts of Interest}

The authors declare no conflicts of interest regarding the publication of this paper.

\section{References}

[1] Gislason, T., Almqvist, M., Boman, G., et al. (1988) Prevalence of Sleep Apnea Syndrome among Swedish Men-An Epidemiological Study. Journal of Clinical Epidemiology, 41, 571-576. https://doi.org/10.1016/0895-4356(88)90061-3

[2] Ip, M.S., Lam, B., Lauder, I.J., et al. (2001) A Community Study of Sleep-Disordered Breathing in Middle-Aged Chinese Men in Hong Kong. Chest, 119, 62-69.

https://doi.org/10.1378/chest.119.1.62

[3] Ali, N.J., Pitson, D.J. and Stradling, J.R. (1993) Snoring, Sleep Disturbance and Behavior in 4-5 Year Olds. Archives of Disease in Childhood, 68, 360-366. https://doi.org/10.1136/adc.68.3.360

[4] The Report of an American Academy of Sleep Medicine Task Force (1999) 
Sleep-Related Breathing Disorders in Adults: Recommendations for Syndrome Definition and Measurement Techniques in Clinical Research. Sleep, 22, 667-689. https://doi.org/10.1093/sleep/22.5.667

[5] Young, T., Palta, M., Dempsey, J., et al. (1993) The Occurrence of Sleep-Disordered Breathing among Middle-Aged Adults. The New England Journal of Medicine, 328, 1230-1235. https://doi.org/10.1056/NEJM199304293281704

[6] Sharma, S.K., Kumpawat, S., Banga, A., et al. (2006) Prevalence and Risk Factors of Obstructive Sleep Apnoea Syndrome in a Population of Delhi, India. Chest, 130, 149-156. https://doi.org/10.1378/chest.130.1.149

[7] Douglas, N.J., Luke, M. and Mathur, R. (1993) Is the Sleep Apnoea/Hypopnoea Syndrome Inherited? Thorax, 48, 719-721. https://doi.org/10.1136/thx.48.7.719

[8] Peppard, P.E., Young, T., Palta, M., et al. (2000) Prospective Study of the Association between Sleep-Disorders Breathing and Hypertension. The New England Journal of Medicine, 342, 1378. https://doi.org/10.1056/NEJM200005113421901

[9] Cheshire, K., Engleman, H., Deary, I., et al. (1992) Factors Impairing Daytime Performance in Patients with Sleep Apnea/Hypopnea Syndrome. Archives of Internal Medicine, 152, 538-541. https://doi.org/10.1001/archinte.1992.00400150068012

[10] Guilleminault, C., Eldridge, L., Tilkian, A., et al. (1977) Sleep Apnea Syndrome Due to Upper Airway Obstruction. Archives of Internal Medicine, 137, 296-300. https://doi.org/10.1001/archinte.1977.03630150020008

[11] Fava, C., Montagnana, M., Favaloro, E.J., et al. (2011) Obstructive Sleep Apnea Syndrome and Cardiovascular Diseases. Seminars in Thrombosis and Hemostasis, 37, 280-297. https://doi.org/10.1055/s-0031-1273092

[12] Borowiecki, B.D. and Sassin, J.F. (1983) Surgical Treatment of Sleep Apnea. Archives of Otolaryngology, 109, 506-512. https://doi.org/10.1001/archotol.1983.00800220014004

[13] Friedman, M., Tanyeri, H., La Rosa, M., et al. (1999) Clinical Predictors of Obstructive Sleep Apnea. Laryngoscope, 109, 1901-1907. https://doi.org/10.1097/00005537-199912000-00002

[14] Clemens, J., McMurray, J.S. and Willging, J.P. (1998) Electrocautery versus Curette Adenoidectomy: Comparison of Postoperative Results. International Journal of Pediatric Otorhinolaryngology, 43, 115-122. https://doi.org/10.1016/S0165-5876(97)00159-6

[15] Marcus, C.L. (2000) Obstructive Sleep Apnea Syndrome: Differences between Children and Adults. Sleep, 23, S140-S141.

[16] Barceló, X., Mirapeix, R.M., Bugés, J., et al. (2011) Oropharyngeal Examination to Predict Sleep Apnea Severity. Archives of Otorhinolaryngology_Head \& Neck Surgery, 137, 990-996. https://doi.org/10.1001/archoto.2011.176

[17] Piumetto, E., Sammartano, A.M., Meinardi, G., et al. (2011) Diagnostic and Therapeutic Iter in Paediatric OSAS: Personal Experience. ACTA Otorhinolaryngologica Italica, 31, 149-153.

[18] Kapusuz, Z., Ozkırış, M., Okur, A., et al. (2012) The Prevalence of Adenoid Hypertrophy in Adults in a Rural Area of Turkey. Kulak Burun Boğaz İhtisas Dergisi, 22, 225-227. https://doi.org/10.5606/kbbihtisas.2012.043

[19] Li, W., Ni, D. and Jiang, H. (1999) Pharyngoscopic Observation during Sleep in Patients with Obstructive Sleep Apnea Syndrome. Chinese Journal of Otorhinolaryngology Head and Neck Surgery, 34, 38-40.

[20] Friedman, M., Ibrahim, H. and Bass, L. (2002) Clinical Staging for Sleep-Disordered 
Breathing. Otolaryngology_Head and Neck Surgery, 127, 13-21. https://doi.org/10.1067/mhn.2002.126477

[21] Li, H.Y., Wang, P.C., Lee, L.A., et al. (2006) Prediction of Uvulopalatopharyngoplasty Outcome: Anatomy-Based Staging System versus Severity-Based Staging System. Sleep, 29, 1537-1541. https://doi.org/10.1093/sleep/29.12.1537

[22] Sher, A.E., Schechtmann, K.B. and Piccirillo, J.F. (1996) The Efficiency of Surgical Modifications of the Upper Airway in Adults with Obstructive Sleep Apnea Syndrome. Sleep, 19, 156-177. https://doi.org/10.1093/sleep/19.2.156

[23] Fibbi, A., Ameli, F., Brocchetti, F., et al. (2002) Combined Genioglossus Advancement (ACMG): Inferior Sagittal Mandibular Osteotomy with Genioglossus Advancement and Stabilization with Suture in Patients with OSAS. Preliminary Clinical Results. ACTA Otorhinolaryngologica Italica, 22, 153-157.

[24] Stow, N.W., Sale, P.J., Lee, D., et al. (2012) Simultaneous Tonsillectomy and Nasal Surgery in Adult Obstructive Sleep Apnea: A Pilot Study. Otolaryngology-Head and Neck Surgery, 147, 387-391. https://doi.org/10.1177/0194599812444256

[25] Schechter, M.S. (2002) Technical Report: Diagnosis and Management of Childhood Obstructive Sleep Apnea Syndrome. Pediatrics, 109, e69.

https://doi.org/10.1542/peds.109.4.e69

[26] Chen, X., Xiao, Y., He, L.C., et al. (2012) Comparation between Modified Coblation Assisted Uvulopalatopharyngoplasty and Conventional Uvulopalatopharyngoplasty in Operative Complication. Chinese Journal of Otorhinolaryngology Head and Neck Surgery, 47, 101-106. 